
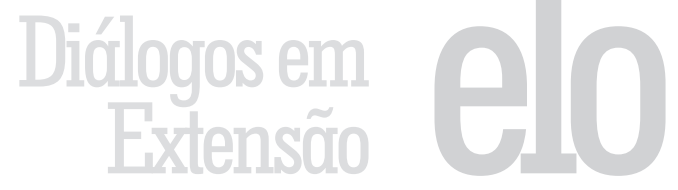

\title{
Juventude e direitos humanos: o uso socialmente útil das mídias sociais
}

Simone Cabral Marinho dos Santos ${ }^{1}$, Ana Maria Morais Costa ${ }^{2}$

Resumo: $O$ projeto de extensão Juventude e Direitos em Rede teve como objetivo contribuir com o estímulo ao uso socialmente útil das mídias sociais na promoção da cidadania e dos direitos humanos. Realizado no município de Campo Grande (RN) durante o ano de 2012, buscou fortalecer o compromisso social e político dos jovens dentro e fora de suas comunidades, com o desenvolvimento de práticas e ações solidárias e cidadãs de potencialização da juventude.

Palavras chave: Direitos humanos, juventude, redes sociais.

Áreas temáticas: Comunicação e direitos humanos.

\section{Youth and human rights: the use socially useful of social media}

Abstract: The extension project Juventude e Direitos em Rede aimed to contribute to stimulus to the use socially useful of social media in promoting citizenship and human rights. It was realized in Campo Grande-RN in 2012 and seeked to strengthen the political and social engagement of young people in and out of their community, with the development of practices and actions of solidarity and civic empowerment of youth.

Keywords: Human rights, social networks, youth.

\section{Juventud y directos humanos: al uso socialmente útil de los medios sociales}

Resumen: El proyecto de extensión Juventude e Direitos em Rede tuvo como objetivo contribuir con el estímulo al uso socialmente útil de los medios sociales en la promoción de la ciudadanía y de los directos humanos. Realizado en el municipio de Campo Grande-RN, en 2012, tiene buscado el fortalecimiento y el compromiso social y político de los jóvenes dentro y fuera de su comunidad, con lo desenvolvimiento de las practicas y acciones solidarias y ciudadanos de potenciación de la juventud.

Palabras clave: Directos humanos, juventud, redes sociales.

1 Professora do Departamento de Educação, da Universidade do Estado do Rio Grande do Norte/ Campus Avançado Prof ${ }^{a}$ Maria Elisa de Albuquerque Maia.

${ }^{2}$ Professora do Departamento de Ciências Sociais da Universidade do Estado do Rio Grande do Norte. 


\section{Introdução}

A construção de uma verdadeira política pública de juventude requer ambientes propícios para o surgimento de uma cultura de participação e cooperação, capaz de criar novos paradigmas para o desenvolvimento da juventude. Enquanto categoria social, como afirma Groppo (2000), a ideia de juventude é vista como uma representação ou criação simbólica produzida pelos grupos sociais ou pelos próprios indivíduos tidos como jovens, para significar uma série de comportamentos e atitudes a eles atribuídos. A categoria juventude apresenta uma especificidade tanto por sua característica mais transitória (idade), quanto por seu contexto sociocultural, demonstrando que o jovem e seu comportamento modificam-se conforme classe social, grupo étnico, nacionalidade, gênero, contextos nacionais e regionais.

Nota-se que a categoria social juventude é uma representação social simbolizada e vivida com muitas diferenças na realidade diária, por assim dizer, mutável e transitória. Não raro, em alguns casos, a juventude vivencia rupturas com padrões culturais pré-estabelecidos, enquanto em outros, reproduz os mesmos modelos. Contudo, seja por vontade própria, seja por condições objetivas da vida social os jovens se mostram dispostos à intervenção, porque é assim que eles se renovam, se organizam e se mobilizam. Para adentrarmos em um ambiente coletivo de compartilhamento de experiências de vida, independente da faixa etária, a que chamamos de geração, o processo de organização é essencial para a formação pessoal e cidadã dos indivíduos.

Por essa razão, a ideia de juventude é construída social e culturalmente e, portanto, mutável conforme o contexto histórico, social, econômico e cultural (CAMACHO, 2004). Com esse propósito, surge o projeto de extensão Juventude e Direitos em Rede possibilitando aos jovens fazerem uma leitura do mundo, do ponto de vista da compreensão do que se passa ao seu redor. Esse projeto foi realizado no município de Campo Grande (RN), no período de fevereiro a junho de 2012, por meio de um curso pautado pelo fortalecimento político e organização social juvenil em diferentes situações e compartilhamento de experiências, na forma de anúncio e denúncia de direitos humanos nas mídias sociais.

A formação foi mediada por meio de oficinas pedagógicas abrangendo os seguintes módulos: 1) Direitos Humanos, Cidadania e Diversidade; 2) Participação Cidadã e Mídias Sociais; 3) Agroecologia, Meio Ambiente e Educação; 4) Participação Social e Protagonismo Juvenil. O tema das mídias e tecnologias sociais perpassou todo o curso, como tema transversal em todos os módulos, com o objetivo de construir uma rede de promoção social e potencialização da juventude. Esse projeto foi executado pela Universidade do Estado do Rio Grande do Norte (UERN), por meio do Núcleo de Extensão em Educação em Direitos Humanos (NUEDH) do 
Departamento de Educação do Campus Avançado Prof ${ }^{a}$ Maria Elisa de Albuquerque Maia, em parceria com ARCI - Comitato Regionale Toscano, Peace Games, ONG Coletivo Quan An, Projeto Dom Helder Câmara/ FIDA/SDT/MDA e Núcleo Sertão Verde.

Como forma de estimular o uso socialmente útil das mídias sociais na promoção da cidadania e dos direitos humanos, esse projeto buscou fortalecer o compromisso social e político dos jovens dentro e fora de suas comunidades, com o desenvolvimento de práticas e ações solidárias e cidadãs de potencialização da juventude. Assim sendo, buscamos expor primeiramente o debate sobre a relação entre direitos humanos, juventude e redes sociais e, em seguida, a vivência e experiência do projeto.

\section{Direitos humanos e formação cidadã}

A natureza humana, a religião, a cultura e a existência de direitos historicamente construídos são diferentes fontes de fundamentação dos direitos humanos. Em cada uma dessas possibilidades de fundamentação, há dois elementos constantes: a igualdade e a dignidade. Pela igualdade, tem-se que os direitos humanos são intitulados por todos os indivíduos pelo mero fato de sua humanidade - característica peculiar a todos os indivíduos. A dignidade da pessoa humana é uma qualidade que precede e limita qualquer ação humana, para além do modo de ser de uma conduta ou do agente. Sua realização tem sempre a igualdade como pressuposto. A perspectiva dos direitos humanos encara a igualdade como inerente à dignidade, daí, o reconhecimento das diferenças, tais como aquelas relacionadas ao gênero, à etnia, à idade etc. Essa perspectiva é reforçada por Bobbio (1992), quando adverte que o próprio homem não é mais considerado um ente genérico, ou homem em abstrato, mas é visto na especificidade ou na concretude de suas diversas maneiras de ser em sociedade, como criança, velho, doente etc.

Segundo Bobbio (1992), numa perspectiva histórica, inicialmente os direitos são atrelados à própria natureza do homem, os quais ninguém supostamente poderia subtraí-los, como o direito à vida, à liberdade, à sobrevivência e à propriedade. Posteriormente, passam a ser direitos positivos, uma vez firmados e reconhecidos nas Constituições de cada Estado e, consequentemente, assumindo caráter universal com a Declaração Universal dos Direitos do Homem, por fazer do indivíduo um sujeito de direito internacional com possibilidade de exigir justiça em uma instância superior contra o próprio Estado.

Embora a universalização tenha marcado o debate sobre os direitos humanos, Bobbio (2000) acena para o caráter da especificação como outra etapa da história da afirmação dos direitos do homem, ambas antecedidas pelas etapas da constitucionalização e da progressiva extensão. Mas, 
tratando-se da etapa da especificação dos direitos, a habitual expressão "direitos do homem" já não é suficiente. Pergunta-se Bobbio (2000): "Que homem?" Assim, demasiadamente genérico, o conceito não atende às especificidades da existência humana "à medida que emergiam novas pretensões, justificadas com base na consideração de exigências específicas de proteção, seja em relação ao sexo, seja em relação às várias fases da vida, seja em relação às condições, normais ou excepcionais, da existência humana" (BOBBIO, 2000, p.482).

Construídas em diferentes momentos históricos, essas etapas são chamadas de Gerações de Direitos Humanos. Na perspectiva de Bobbio (2000), foram quatro gerações. A primeira geração caracterizou-se pela afirmação dos Direitos Individuais, pressupondo o indivíduo com fonte de direito e igualdade perante a lei. A segunda, dos Direitos Sociais, dos quais derivam expectativas legítimas da convivência entre os indivíduos em sociedade, visto no seu contexto social e em uma situação concreta. A terceira geração diz respeito aos Direitos dos Povos ou os Direitos de Solidariedade. Por fim, a quarta geração trata dos Direitos de Manipulação Genética relacionados à biotecnologia e bioengenharia, motivados por uma discussão ética prévia (BOBBIO, 1992).

Os esforços e as iniciativas desencadeados pela busca do reconhecimento e proteção dos direitos humanos, embora tenham passado por várias fases, segundo Bobbio (1992, p. 05), nascem "em certas circunstâncias, caracterizadas por lutas em defesa de novas liberdades contra velhos poderes, e nascidos de modo gradual, não todos e uma vez e nem de uma vez por todas". Assim também acontece com a forma lenta e gradual de efetivação dos direitos humanos. De todo modo, há progressos evidentes de promoção e defesa dos direitos humanos que tem privilegiado o diálogo, a parceria e a cooperação no lugar da pressão e do confronto.

No Estado moderno, o indivíduo é fonte de poder e titular de direitos, o sujeito central da esfera política. Com a Declaração Universal dos Direitos Humanos em 1948, observa-se que os direitos políticos, sociais, culturais, econômicos, civis e sociais declarados confrontam-se com a ordem social estabelecida, o que se permite pensar em uma nova dimensão democrática dos direitos. Para isso, é necessária a existência de mecanismos e instrumentos favoráveis à garantia desses direitos. Desenvolver práticas capazes de dar voz aos sujeitos é um ponto forte do campo do exercício dos direitos.

Destaca-se aqui o papel da sociedade nas diferentes reivindicações em favor do exercício desses direitos. Assim, representação política, liberdade civil e participação têm sido a tônica das reivindicações democráticas que ampliaram a questão da cidadania, fazendo-a passar do plano político institucional ao da sociedade como um todo. Como é função precípua do Estado a prestação de atendimento jurisdicional, fundamento básico do 
Estado de Direito, entende-se que, para o integral acesso à justiça, se faz também necessário conhecimento e informação sobre os direitos, dado que os deveres, principalmente o de obediência às leis, sempre vieram em todos os tempos antes dos direitos. A perspectiva da conquista não ocorre de forma isolada e envolve sempre alguma forma de reivindicação. Em outras palavras, os direitos civis dependem da existência dos direitos políticos que, por sua vez, dependem da existência de regimes efetivamente democráticos (COSTA, 2010).

No seio das lutas, reivindicações e conquistas, com caráter distinto e atividades diversas, a formação cidadã da juventude é permeada por uma multiplicidade de acepções e por excelência no espaço da práxis. Formação essa capaz de proporcionar uma educação para a vida que, dentre outras competências e atitudes, significa perceber-se como sujeito de suas ações, como ser ativo, crítico e criativo, apto a intervir na realidade com qualidade técnica e política (DEMO, 2000). Na formação para cidadania, os processos educativos se organizaram a partir de temas emergentes e, ao mesmo tempo, do estabelecimento de diálogos com redes de mobilização que protagonizam a vivência e o exercício da cidadania coletiva, construída a partir dos grupos organizados da sociedade civil, tendo como foco central os interesses da coletividade de diversas naturezas. Desse modo, a educação para a cidadania como princípio fundamental é apoiada nos princípios de democracia e da justiça social e desenvolvida como uma ação socioeducativa, perpassada por uma visão de mundo, de sociedade e de uma época, constituindo-se como prática educativa no âmbito do projeto de globalização contra-hegemônico e alternativo.

A ausência de espaços de participação e formação cidadã na sociedade contemporânea constituiu-se num grande desafio para educadores e sujeitos sociais comprometidos com a permanente luta pela conquista e exercício da cidadania e vivência democrática. Os cenários construídos apresentam demandas confusas para a juventude e distanciadas das possibilidades de participação política e exercício cidadão na perspectiva de construção de uma sociedade de iguais (COSTA, 2010).

A juventude da primeira década do século XXI vive uma significativa imersão na realidade virtual. Essa realidade cria a sensação de estar dentro, de participar ativamente como membro daquele mundo, uma vez que tudo se encontra virtualmente à disposição. O desenvolvimento da tecnologia possibilita uma interação tão intensa que o indivíduo concentra-se mais na existência do ambiente virtual que no seu ambiente real.

Uma das conseqüências é o distanciamento progressivo que marca o convívio face a face entre os indivíduos, caracterizando o que Elias (2001) chama de "esfriamento" das relações sociais. Para esse autor, uma característica das sociedades contemporâneas, especialmente daquelas mais desenvolvidas, é o afastamento daquele que é mais próximo, criando 
novas formas de segregação social, levando os indivíduos a se verem em posições absolutamente apartadas da realidade social. Tomando como referência o conceito de Elias (2001), mas nos distanciando do contexto e das particularidades estudadas pelo autor ao tratar da velhice e da morte na sociedade contemporânea, esse esfriamento provoca e cria novas formas de sociabilidades e de convívio exclusivo entre os indivíduos.

Aqui situamos o ambiente virtual como uma forma de sociabilidade, enquanto vivência diversificada e desenvolvimento das habilidades e potencialidades individuais e coletivas. Nesse ínterim se forma e se faz a juventude, gestora de novas significações no ambiente virtual, em que se socializa e aprende. No cerne dessa sociabilidade, com caráter distinto e atividades diversas, que oportunidades para o exercício da práxis esses jovens teriam? Quais espaços encontrariam para a convivência com a diferença, formulação e condução das reivindicações, (re)organização do discurso, transformação das carências sociais em direitos, construção de estratégias para acionar a capacidade provedora do Estado? Partimos do princípio que as formações política e cidadã ocorrem na vivência e nos diversos espaços políticos e sociais que aglutinam sujeitos sociais, os quais, por meio de suas organizações políticas e culturais, lutam, constroem e efetivam conquistas de cidadania que, ao mesmo tempo, possibilitam diminuir a distância entre o que se diz e se faz.

Tomando como referência o ambiente virtual, na interação com diversos espaços de opinião, denúncias e mobilizações, há uma infinidade de comunidades relacionadas aos direitos de cidadania, à solidariedade humana e uma diversidade de formatos de participação. Formar jovens para o compromisso social e político, comprometidos com o processo histórico dos seus municípios, estados e país, exige a criação e o fortalecimento de espaços efetivos que proporcionem o desenvolvimento de práticas e ações solidárias e cidadãs. Em meio a esses desafios, ganha espaço as mídias e redes sociais. As carências são transformadas em demandas e reivindicações, transformando o ambiente virtual num espaço socialmente útil para a promoção da cidadania e dos direitos humanos.

\section{Extensão universitária, juventude e redes sociais}

A construção do conhecimento gerado pela Extensão no âmbito universitário tem provocado uma mudança qualitativa e transformadora na relação entre Universidade e Comunidade, pela via da aprendizagem e socialização do saber, aliando o conhecimento técnico e especializado à valorização da perspectiva da promoção humana. Isso é possível ao se tratar Extensão Universitária como uma atividade acadêmica, "parte do processo orgânico e contínuo que se estende desde a produção até a sistematização e a transmissão do conhecimento" (NOGUEIRA, 2001, p.71). 
Desmitifica-se, então, a sequência difusionista de que a pesquisa é geradora da extensão, quando nos defrontamos com a produção do conhecimento integrada socialmente, pela via da indissociabilidade entre o ensino, a pesquisa e a extensão, expressão do compromisso social da Universidade com a Sociedade. Como diria Toscano,

a extensão poderá permitir, desse modo, a troca de saberes sistematizados, acadêmicos e populares, a democratização do conhecimento veiculado na Universidade, a participação efetiva da comunidade em suas atividades, bem como a produção de novos conhecimentos a partir do contato com a realidade (TOSCANO, 2006, p.33).

Considerando tais pressupostos, cabe à universidade definir a sua política de extensão, a viabilidade de suas formas de relações com os setores da sociedade civil e política e a contribuição para a construção de um projeto de mudança social. Em se tratando do desenvolvimento de uma política de extensão universitária voltada para os jovens, há que considerar o caráter plural da categoria social juventude. Há diferentes tendências para se compreender essa categoria oscilando entre, de um lado, a que toma a juventude como um conjunto social, cujo atributo principal é ser constituído por indivíduos pertencentes a uma determinada fase da vida; de outro, a que entende a juventude como um conjunto social necessariamente diversificado, que abrange diferentes culturas juvenis decorrentes de diferentes pertencimentos de classes, com diferentes parcelas de poder, com diferentes interesses ou diferentes situações econômicas (CAMACHO, 2004).

Embora a tendência geracional seja mais homogeneizada, entendemos a categoria juventude como socialmente construída, inventada que se faz a partir de um processo histórico permeado pelas experiências do seu contexto social. A um só tempo, caracteriza e exterioriza os diferentes percursos que a condição juvenil experimenta a partir dos mais diversos recortes de gênero, classe, etnia.

Uma política de integração da juventude busca promover uma efetiva inserção dos jovens na sociedade e fomentar uma ampla participação juvenil no processo de desenvolvimento local. Recentemente, foi aprovado no Congresso Nacional o Estatuto da Juventude. A Lei $\mathrm{n}^{\circ} 12.852$, de 05 de agosto de 2013 estabelece direitos e políticas públicas voltadas à população entre 15 e 29 anos. Esse Estatuto reafirma direitos já previstos em lei, como educação, trabalho, saúde e cultura, como também assegura novos direitos, a exemplo da participação social e da livre orientação sexual, atendendo necessidades específicas dos jovens, respeitando as 
suas trajetórias e diversidade. Com o Estatuto, temos o desafio de fortalecer práticas abertas de promoção da cidadania e emancipação política do jovem.

Sob a égide da participação e da emancipação do jovem, desenvolvemos o projeto de formaçãoJuventude e Direitos em Rede, realizado no município de Campo Grande, estado do Rio Grande do Norte, no período de fevereiro a junho de 2012, por meio de um curso pautado pelo fortalecimento político e organização social juvenil.

O projeto Juventude e Direitos em Rede tinha como objetivo estimular o uso socialmente útil das mídias sociais, já que a grande maioria dos participantes dessa ação extensionista não utilizava as redes sociais como instrumento para a promoção da cidadania e dos direitos humanos. Esse projeto foi executado pela Universidade do Estado do Rio Grande do Norte (UERN) por meio do Núcleo de Extensão em Educação em Direitos Humanos (NUEDH), do Departamento de Educação do Campus Avançado Profa Maria Elisa de Albuquerque Maia, em parceria com ARCI Comitato Regionale Toscano, Peace Games, ONG Coletivo Quan An, Projeto Dom Helder Câmara/FIDA/SDT/MDA e Núcleo Sertão Verde.

As três primeiras parcerias justificaram-se em razão do diálogo e da articulação que temos travado com a ONG Coletivo Quan An, enquanto executora, no Brasil, das ações do ARCI - Comitato Regionale Toscano e Peace Games - Uisp, desde a participação de membros da equipe do projeto no seminário sobre Juventude, realizado em 2010, em Florença (Itália). O referido seminário foi promovido pelo ARCI, visando sensibilizar profissionais da cooperação internacional sobre o tema dos direitos da criança e do adolescente no mundo e, especialmente, na América Latina. Nesse seminário foi possível divulgar ações na área da formação da juventude, dentre elas o projeto de extensão Escola de Formação Política e Cidadã (2007 a 2009) e o projeto Cursinho Abrindo Caminhos, em execução desde 2008 no município de Campo Grande (RN), com o objetivo de estimular o acesso de jovens ao ensino superior por meio de um cursinho popular. As duas últimas merecem destaque em função da continuidade da proposta, da sua área de abrangência e da afinidade com o projeto coletivo de formação para juventude.

A formação foi mediada por meio de oficinas pedagógicas abrangendo os seguintes módulos: 1) Direitos Humanos, Cidadania e Diversidade; 2) Participação Cidadã e Mídias Sociais; 3) Agroecologia, Meio Ambiente e Educação; 4) Participação Social e Protagonismo Juvenil. O tema das mídias e tecnologias sociais perpassou todo o curso, como tema transversal em todos os módulos, com o objetivo de construir uma rede de promoção social e potencialização da juventude. Como produtos, os alunos foram estimulados a desenvolverem, individualmente ou em grupo, blogs engajados sobre temas relevantes para suas comunidades e seu território, 
campanhas sociais e de promoção de direitos nas comunidades e escolas, produção de textos, noticiários para o rádio, dentre outros. Durante o Curso foi criado o grupo no Facebook Juventude e Direito em Rede.

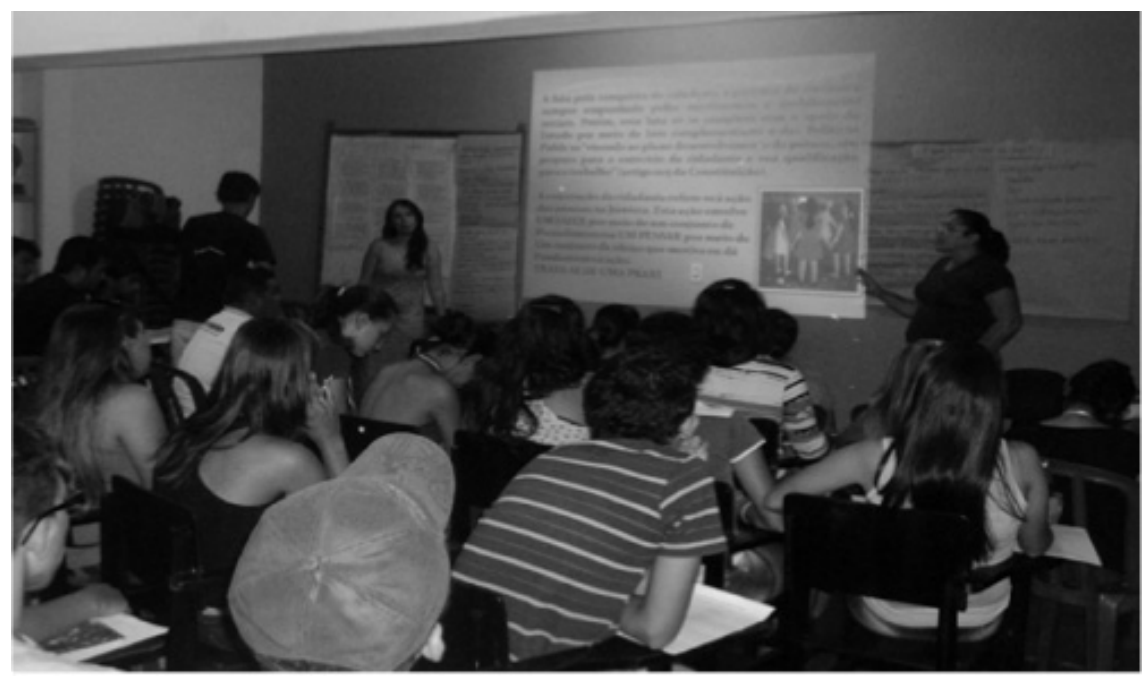

Figura 1: Fotografia da Oficina Cidadania, Direitos Humanos e Diversidade/ Ano 2012 Fonte: Arquivo do Projeto Juventude e Direito em Rede

Com o intuito de conhecer a forma de acesso e nível de inclusão digital dos jovens participantes do projeto, realizamos um breve diagnóstico no início do curso (março de 2012) para efeito de direcionamento e planejamento das atividades. Dos 71 inscritos no curso, participaram desse diagnóstico 49 jovens. Destes, 19 homens e 30 mulheres. Dos 49 jovens entrevistados, 10 moram na zona rural e 25 atuam em algum tipo de instituição e/ou organização social como igreja, ONG, partido político, movimento social, associação rural, grupo de teatro, dentre outros. Tratando-se do acesso e nível de inclusão digital dos jovens, verificamos primeiramente que $53 \%$ usam o computador todos os dias, enquanto $31 \%$ usam uma ou duas vezes por semana.

No que diz respeito à freqüência de acesso à internet, $49 \%$ acessam todos os dias, $31 \%$ uma ou duas vezes por semana e $20 \%$ eventualmente ou nunca acessam a internet. A principal justificativa para o não acesso à internet está na carência de um local que possibilite esse acesso. Já para os que utilizam a internet com maior frequência, o principal local de acesso é a própria casa (51\%) ou a casa de outra pessoa conhecida (45\%). Sobre as ferramentas das redes sociais, verificamos que $92 \%$ possuem e-mail, $88 \%$ estão no orkut, $51 \%$ no facebook e $55 \%$ tem twitter. Entre as principais razões, motivos e finalidades do acesso à internet, destacam-se: fazer algum tipo de pesquisa, acessar orkut e facebook, acessar blog, ler e responder e-mails, lazer, dentre outros. 
Embora verifiquemos uma significativa popularização da internet entre esses jovens, o acesso não tem sido acompanhado por um processo educativo que faça do ambiente virtual uma força em favor do desenvolvimento pessoal e coletivo. $\mathrm{O}$ acesso à informática continua limitado na quantidade e também na qualidade do seu uso. Pensando nos limites do uso social das redes sociais, os módulos do curso foram desenvolvidos com atividades práticas que envolvessem a utilização de mídias sociais, contabilizadas nas horas não presenciais.

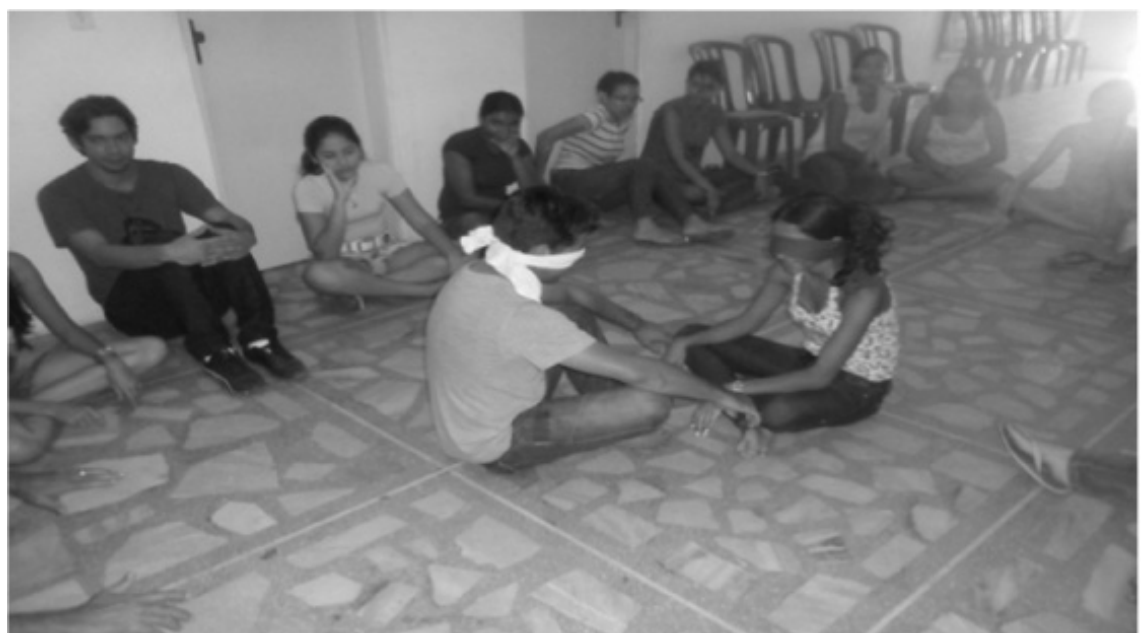

Figura 2: Fotografia da Participação Social e Protagonismo Juvenil /Ano 2012 Fonte: Arquivo do Projeto Juventude e Direito em Rede

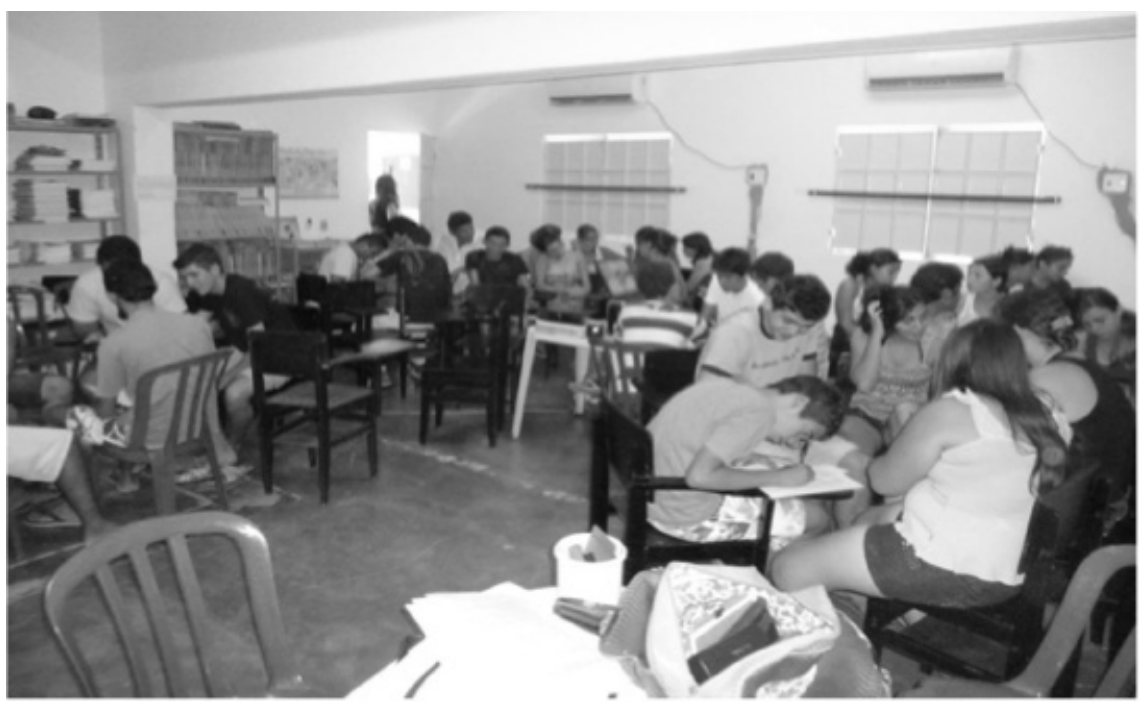

Figura 3: Fotografia da Oficina Agroecologia, Meio Ambiente e Educação/Ano 2012 Fonte: Arquivo do Projeto Juventude e Direito em Rede 
Como proposta de atividades práticas do curso, os participantes foram estimulados a pensar e executar as ações como agentes multiplicadores. Intitulamos essas atividades práticas de "Vamos passar adiante essa ideia". As propostas foram as seguintes:

- Participação nas atividades previstas para Semana do Meio Ambiente (junho/2012) em Campo Grande, por meio do plantio de mudas, em parceria com a Visão Mundial, além do trabalho de conscientização sobre a poluição do Rio Upanema e discussão sobre a erradicação das casas de taipa no meio urbano e rural;

- Criação do Fórum Juventude e Direitos em Rede via facebook;

- Divulgação e promoção do tema dos direitos humanos em rádios, escolas, campanhas, blogs, a partir da criação de uma radionovela sobre Bullying e Preconceito, atividade prática de uma oficina.

- Produção textual a ser vinculada nos blogs, a exemplo dos textos escritos pelos alunos intitulados "Exploração Sexual" e “Tráfico de Pessoas", publicados em blogs de alcance regional.

- Produção de Peça de Teatro "Relações de Gênero no tempo dos nossos pais e avós".

As ações do projeto foram divulgadas e acompanhadas através das ferramentas virtuais, a partir do registro da quantidade diária de retweets, de páginas curtidas, de posts curtidos, de comentários aos posts das redes sociais e dos blogs, de seguidores ativos que interagem (ou seja, o alcance da discussão que eles conseguiram levantar no ciberespaço). Além do aspecto quantitativo, registrava-se a natureza e os conteúdos dessas interações (quais posts foram mais comentados/compartilhados; quais discussões foram mais alimentadas etc.).

\section{Estratégia da ação}

O projeto Juventude e Direitos em Rede foi realizado no período de 10 de março a 30 de junho de 2012, na sede do Núcleo Sertão Verde, município de Campo Grande (RN). A mobilização para sua elaboração, definição de parcerias e inscrição de participantes deu-se início em fevereiro do corrente ano. Com 71 inscrições, o projeto iniciou em 10 de março de 2012 com 49 participantes. Destes, concluíram 30.

O projeto foi desenvolvido por meio de um curso, destinado a jovens ligados ou não a movimentos e/ou organizações sociais, mas que tinham interesse na área dos direitos humanos e na formação política da juventude, por meio da utilização social das ferramentas virtuais. O curso teve uma carga horária de 50 horas-aula, subdividido em quatro módulos. Destas 50 horas-aula, 08 horas-aula foram destinadas às atividades não presenciais, programadas e executadas durante o desenvolvimento do projeto. Durante as oficinas foram explorados recursos como as dinâmicas 
de grupo, exposição dialogada dos temas, músicas, poemas, radionovelas, filmes, dentre outros. A forma de divulgação do curso se deu por meio de cartazes vinculados nas redes sociais, avisos na rádio local e notícias.

O primeiro módulo do curso desenvolveu a temática "Direitos Humanos, Cidadania e Diversidade", tendo como conteúdos principais a discussão sobre a definição, natureza e prática dos direitos humanos, da cidadania, da juventude e sexualidade, com carga horária de 08 horas-aula. O segundo módulo abordou "Participação Cidadã e Mídias Sociais", quando se discutiu a ideia de participação social e tecnologias sociais, inclusão digital, mídias sociais, produção e sistema de relacionamentos digitais. Esse módulo, com carga horária de 8 horas-aula, foi transmitido pela internet em tempo real, com interação entre os participantes. O terceiro módulo explorou "Agroecologia, Meio Ambiente e Educação", tratando de temas como gênero, geração, agricultura familiar, agroecologia e educação ambiental, com carga horária de 16 horas-aula. O quarto módulo se dedicou à temática "Participação Social e Protagonismo Juvenil”, tendo como principais discussões as políticas públicas para juventude, a formação de lideranças juvenis, ações cidadãs e acompanhamento das mídias sociais, com carga horária de 10 horas-aula. Após a realização das oficinas, foi desenvolvido pelos jovens o planejamento de ações cidadãs nas mídias sociais, executado no mês de junho, contabilizando uma carga horária de 08 horas-aula não presenciais.

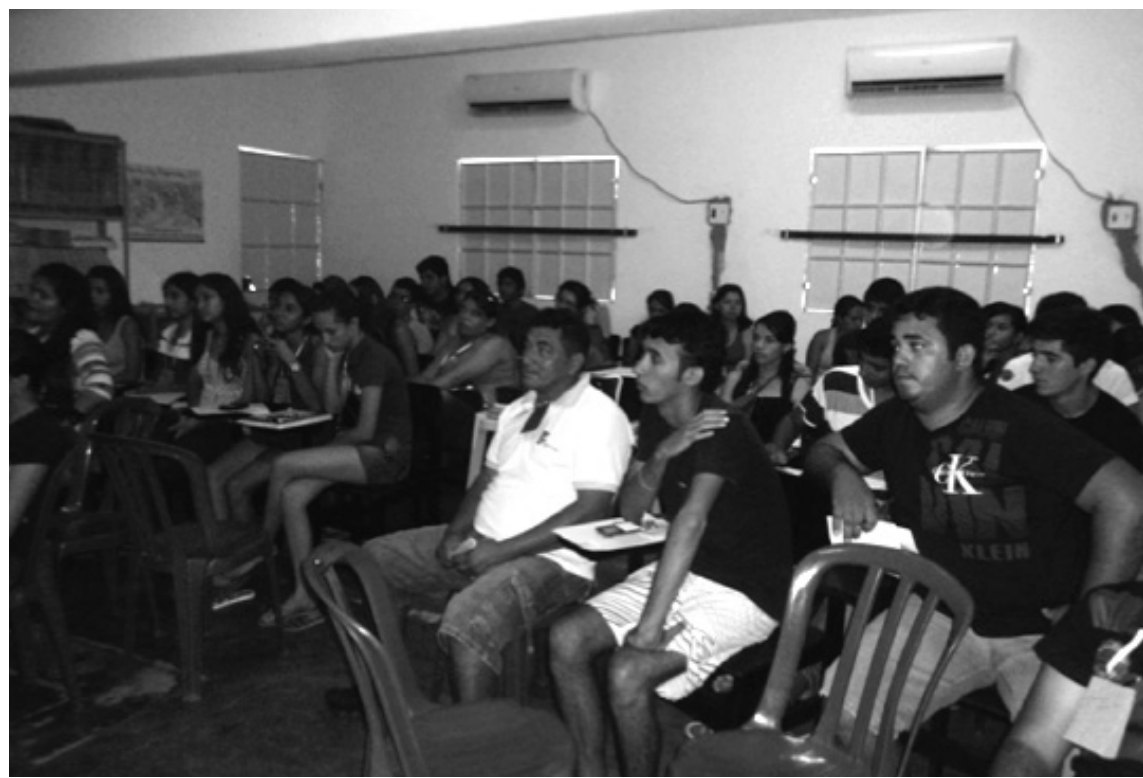

Figura 4: Fotografia da Oficina de acompanhamento das ações de cidadania e mídias sociais/Ano 2012

Fonte: Arquivo do Projeto Juventude e Direito em Rede 


\section{Resultados da ação}

Pudemos constatar no desenvolvimento do projeto Juventude e Direitos em Rede os seguintes resultados:

- Animação do processo de formação política da juventude a partir da utilização social do espaço virtual.

- Participação ativa na construção de conhecimento e atividades práticas pelos cursistas, na medida em que os temas diretamente abordados eram ligados ao cotidiano deles.

- Envolvimento da turma no twitter e no facebook relatando os benefícios com as discussões e principalmente com as dicas e ferramentas práticas apresentadas no curso.

- Publicação de textos em blogs.

Maior interação nas redes sociais, permitindo o acompanhamento e o desenvolvimento das atividades por meio da resolução de problemas, solução de dúvidas, para dar dicas etc.

\section{Considerações Finais}

Nos diversos espaços sociais de formação cidadã e participação política, os sujeitos envolvidos aprendem e exercitam a cidadania, a democracia e a justiça social como componente central de um novo aprendizado no campo dos direitos humanos. O favorecimento de espaços sociais de formação na universidade passa por questões como: noção de cidadania que a universidade deve adotar nos processos de formação; maior aproximação da universidade com seu entorno social, com ações de extensão como eixo estruturante de formação para e pela cidadania; construção de uma nova mentalidade educativa que supere a visão academicista que ainda persiste, de que o desenvolvimento de ações no campo do ensino, da pesquisa e da extensão envolvendo temáticas como direitos humanos, participação, cidadania, diversidade cultural, dentre outros, são iniciativas de sujeitos que tenham algum engajamento político e social. O conjunto dessas ausências é refletido diretamente na formação dos estudantes e, consequentemente, na sua futura atuação como profissionais e como sujeito na vida social.

Logicamente, a ação educativa não ocorre nessa linearidade porque as interações sociais engendram novos arranjos formativos. Ela é capaz de desenvolver e adquirir conhecimento de sua própria prática, aprendendo a ler e interpretar o mundo que os cerca. As redes sociais apresentam-se como um campo de possibilidades para arranjos formativos baseados na participação política e formação cidadã para juventude.

Embora reconheçamos o inegável poder de utilização das redes sociais como um suporte para anúncio e denúncia de direitos humanos, em linhas gerais, o acesso à internet pelo jovem não tem sido acompanhado 
por um processo educativo que faça desse instrumento virtual uma força em favor do desenvolvimento pessoal e coletivo. $\mathrm{O}$ acesso à informática continua limitado na quantidade e também na qualidade do seu uso, apesar da significativa animação do processo de formação política da juventude, a partir da utilização social do espaço virtual, a partir da produção de textos e potencialização de blogs engajados de promoção e defesa dos direitos humanos.

Uma das dificuldades para realizar essas atividades se manifestava na falta de reuniões, de encontros entre os cursistas após as oficinas para planejamento e execução das ações. Além disso, havia os interesses e disputas políticas locais interferindo na organização do grupo. Aliás, o acompanhamento dessas atividades foi uma das grandes dificuldades do projeto, que se agravava em função da rotatividade da participação dos jovens nas oficinas. Como estas eram divulgadas nas redes sociais, houve o estímulo involuntário à participação de outros jovens nas oficinas, por tema de interesse, dificultando o controle da participação. Por outro lado, servia para despertar a curiosidade e interesse de entrar no projeto, caso fosse o desejo do participante.

Outra atividade prevista era a realização do "I Seminário Juventude e Direitos em Rede", para efeito de culminância das atividades, práticas e desdobramentos encaminhados nas oficinas, reunindo os jovens participantes do projeto, representações da juventude do território Sertão do Apodi e entidades parceiras da ação. Essa ação dependia de recursos repassados pela ARCI Toscana e Peace Games, bem como da participação de seus representantes nas atividades do projeto. Como não houve repasse dos recursos financeiros previstos, não foi possível realizar o seminário.

Vale ressaltar que parte do projeto foi desenvolvida em plena efervescência do movimento de greve dos docentes, técnicos e alunos da UERN, porque a vinda desses representantes dependia que esse projeto estivesse em andamento. Contudo, não descartamos a possibilidade de realizá-lo, tendo em vista a execução de futuros projetos de extensão a serem realizados no território Sertão do Apodi. Com a falta de repasse dos recursos durante a execução do projeto, as despesas com locomoção e estada dos facilitadores foram custeadas por estes, assim como as despesas com o lanche dos participantes pelo Núcleo Sertão Verde.

Como já abordado, reafirmamos o uso socialmente útil das mídias sociais para promoção de direitos humanos e estímulo à participação social, por ser uma ferramenta de inovação com grande potencial formador. Podemos dizer que a criação de estratégias de intervenção e reflexão de conteúdos presentes nessas mídias produz conhecimento coletivo, resultante da formação e da experiência de vida dos sujeitos. 


\section{Referências Bibliográficas}

BORDENAVE, J.E.D. O que é participação. Coleção Primeiros Passos. São Paulo: Brasiliense, 2007.

BOBBIO, N. Teoria geral da política: a filosofia política e as lições da política. Rio de Janeiro: Campus, 2000. . A era dos direitos. Rio de Janeiro: Campus, 1992.

CANDAU, V.M.F.; SACAVINO, S. Educação em Direitos Humanos.In: CANDAU, V. M. F.(Org.). Magistério: construção cotidiana. Petrópolis-RJ: Vozes, 2003.

CAMACHO, L.M.Y. A invisibilidade da juventude na vida escolar. Perspectiva, Florianópolis, v.22, n.02, jul./dez., p.325-343, 2004. Disponível em: http://www.ced.ufsc.br/nucleos/nup/perspectivas.html. Acesso em: 21 ago. 2013.

CHAUÍ. M. A Universidade Pública sob nova perspectiva. Conferência de abertura da ANPED. Poços de Caldas, 2000.

COSTA, A.M.M. Fazendo história: formação da juventude e participação política. In: SÁ, V.C.; SANTOS, S.C.M.S. (Orgs). Extensão universitária, juventude e formação: experiência e prática educativa em espaços não escolares. . Mossoró-RN: Edições UERN, 2010.

DALLARI , D.A.O que é participação política.Coleção Primeiros Passos; p.104. São Paulo: Brasiliense, 1999.

DEMO, P. A Nova LDB:ranços e avanços. 10. ed. Campinas, SP: Papirus, 2000.

ELIAS, N. A solidão dos moribundos. Rio de Janeiro: Jorge Zahar Editor, 2001.

FREIRE, P. Pedagogia do oprimido. $41^{\mathrm{a}}$ ed. Rio de Janeiro: Paz e Terra, 2005.

GOHN, M.G. Teoria dos movimentos sociais. São Paulo: Loyola, 1997.

. História dos movimentos e lutas sociais: a construção da cidadania dos brasileiros. São Paulo: Loyola. 1995.

GROPPO, L. A juventude: ensaios sobre sociologia e história das juventudes modernas. Rio de Janeiro: Difel, 2000.

MANZINI COVRE. M.L. O que é cidadania. Coleção Primeiros Passos. São Paulo: Brasiliense, 2001.

NOGUEIRA, M.D.P. Extensão Universitária no Brasil:uma revisão conceitual. In: FARIA, D.S. (Org.). Construção Conceitual da Extensão Universitária na América Latina. Brasília: UnB, 2001. 
TOSCANO, G.S. Extensão universitária e formação cidadã: UFRN e UFBA em ação. 2006. 293 f. TESE (Doutorado em Ciências Sociais). Curso de Pós-Graduação em Ciências Sociais, Universidade Federal do Rio Grande do Norte. Natal RN. 2006.

SÁ, V.C.; SANTOS, S.C.M.S. (Orgs). Extensão universitária, juventude e formação: experiência e prática educativa em espaços não escolares. Mossoró-RN: Edições UERN, 2010.

SANTOS, B.S. Os direitos humanos na zona de contacto entre globalizações rivais. Cronos: Revista do Programa de Pós-Graduação em Ciências Sociais da UFRN, Natal-RN, v.08, n.1, jan./jun., p.23-40, 2007. 